\title{
ANALYSIS FOR PRECIPITATION CLIMATE PREDICTION ON SOUTH OF BRAZIL
}

Simone E. T. Ferraz ${ }^{1}$, Roberto P. Souto ${ }^{2}$, Pedro L. S. Dias², Haroldo F. de Campos Velho ${ }^{3}$, Heloisa M. Ruivo ${ }^{3}$

\author{
${ }^{1}$ Universidade Federal de Santa Maria (UFSM), Brazil \\ ${ }^{2}$ Laboratório Nacional Computação Científica (LNCC), Brazil \\ ${ }^{3}$ Instituto Nacional de Pesquisas Espaciais (INPE), Brazil.
}

simonetfe@gmail.com,rp.souto@gmail.com,pldsdias@lncc.br, haroldo@lac.inpe.br, heloisa.ruivo@lac.inpe.br

\begin{abstract}
An evaluation for the precipitation climatology for the Rio Grande do Sul state (Brazil) is performed. The BRAMS code is feeded with boundary conditions from the CPTEC-INPE global circulation model (GCM). The simulated precipitation for this region in Brazil presented a climate standard diferent from the observations. An spectral analysis on the wind was carried out to explain the desagreement.
\end{abstract}

Resumo: Uma avaliação para a climatologia de precipitação para o estado do Rio Grande do Sul (Brasil) é realizada. As condições de contorno para o código BRAMS são providas pelo modelo de circulação global do CPTEC. Precipitação simulada difere das observações. Uma análise espectral das componentes do vento é empregada para explicar a discrepância registrada.

\section{INTRODUCTION}

The CLIMARS project is a multi-institutional project funded by the FINEP, a Brazilian agency for research support. The project is focused on the evaluation of the impact of different climate conditions on the Rio Grande do Sul (RS) state, Brazil (Campos Velho et al., 2012). For this evaluation, three IPCC (Intergovernmental Panel on Climate Change) scenarios are considered: (a) A2 (busyness as usual), (b) A1B (moderate enhancing of anthropogenic gas emissions), (c) B1 (severe enhancing of anthropogenic gas emissions). The strategy to perform the study employs three basic features: (a) grid computing 
infrastructure, connecting computer centers for four institutions placed in different cities in the Rio Grande do Sul state: INPE and UFSM (Santa Maria), UFPel (Pelotas), UFRGS (Porto Alegre); (b) dynamical downscaling; (c) ensemble prediction.

The meteorological regional model BRAMS (Brazilian Regional Atmospheric Model System) is described in Freitas et al. (2009). BRAMS is one of the operational models for short and medium range forecasting at CPTEC-INPE. This model is the tool for carrying out the dynamical downscaling from the IPCC scenarios.

\section{DOWNSCALING WITH BRAMS}

The grid processing is employed to compute the 10-year climatology and the long range simulations under the ensemble methodology. This approach was tested during the GBRAMS project, and Almeida et al. (2013) show the results.

Long range time integrations of BRAMS simulations will provide data for some climate analysis, and for numerical integration of different models: (a) extreme events regimes, (b) MGB-IPH (hydrological) model, (c) InfoCrop: model calibrated for Southern Brazil with three agriculture crops to be analyzed (rice, soybean, and corn). The boundary conditions are provided from CPTEC-INPE global model, where 5 members (meaning, 5 different initial conditions) are integrated for 10 years (period: 1992-2001). The climatology is calculated using an ensemble with 3-members (3 different dates for initial condition).

\section{RESULTS AND FINAL COMMENTS}

The process for generating the climatology and the long range integration was started. But, the results did not reproduce the climate conditions verified on this part of Brazil (from observation: wet winter, and dry summer - the climate standard for most part of Brazil is: dry winter, with wet summer. Figure 1a shows the accumulated predicted precipitation at July-2009, for ensemble member-1 from the GCM-CPTEC. This is a very dry condition. 


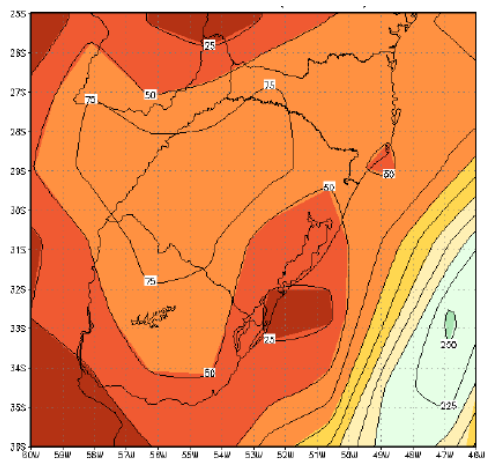

(a)

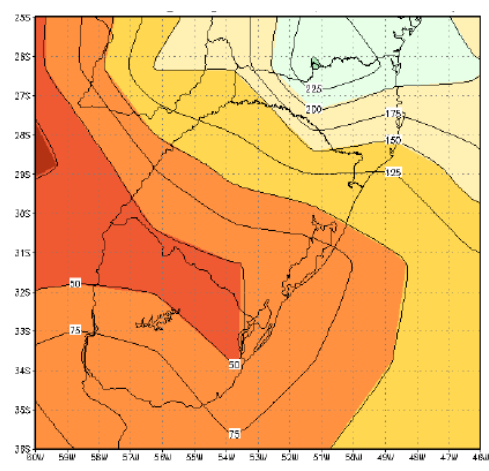

(b)

Figure 1: Accumulated precipitation at July-2009: (a) ensemble member-1 from the CGMCPTEC, (b) re-analysis NCEP.

In order to obtain a climate pattern more similar to the observations, several options were examined: (i) enhancing the soil moisture, (ii) increasing the nudging parameter, (iii) another estimate of the SST, (iv) change the boundary condition to the data provided by the GCMNCEP (National Center for Environment Prediction, USA). For all options, the precipitation field remained much below the observations. Figure $1 \mathrm{~b}$ displays the accumulated precipitation from the GCM-NCEP.

Our conclusion was the global models are not able to reproduce appropriate boundary conditions for this region. This issue represents a new challenge for the modelers. However, it is not clear what feature was failing. One idea was to evaluate the energy associated to the transient forcing associated to the wind. One mechanism for transporting water vapor in the North/South direction, connecting the Amazon and the La Plata Basin, where most of the RS state is located, is associated to transients in the wind field that are characterized by periods with strong N/NW flow along the Andes, replaced by other periods with strong S/SE flow. Figure 2 shows a spectral analysis for the meridional wind component at a grid point $\left(30^{\circ} \mathrm{S}\right.$, $60^{\circ} \mathrm{W}$ ), over Argentina, east of the Andes at about the same latitude as the RS state. It is clear that global model fails to reproduce the energy in the transients that transport wet air from the North region to the South region in the Brazil, primarily in the intraseasonal time scale (i.e., periods > 10 days), the lower levels (e.g. $1000 \mathrm{mb}$ ). The lack of forcing in the intraseasonal scale is considered to be a major drawback in the global simulation. 


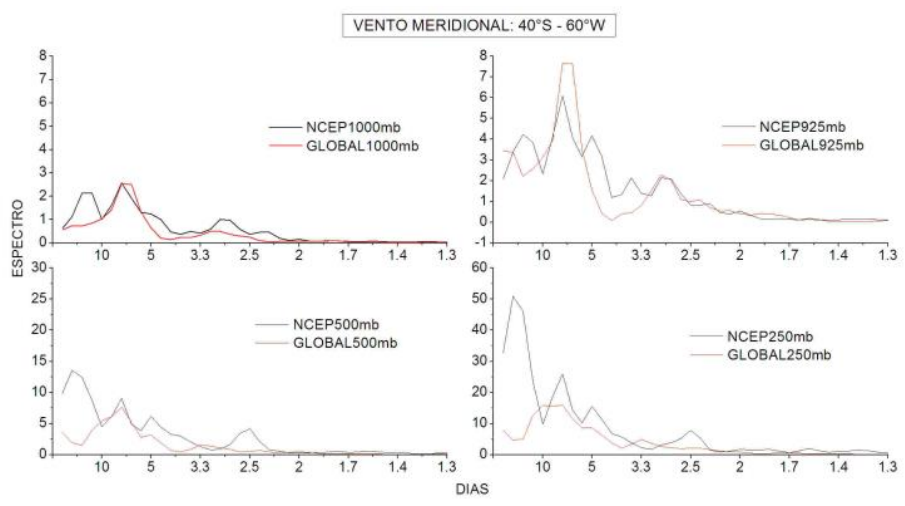

Figure 2: Spectra for meridional wind component.

\section{REFERENCES}

CAMPOS VELHO, H. F., et al. Mesoscale Climate Evaluation Using Grid Computing, Geophysical Research Abstracts, Vol. 14, EGU2012-13758-1, EGU General Assembly, Austria, 22-27 April, 2012.

ALMEIDA, E. S., CAMPOS VELHO, H. F., PRETO, A. J. Challenges for mesoscale climatology execution on experimental grid computing systems. J. Braz. Computer Soc., (19)3, 279-290, 2013.

FREITAS, S. R. et al. The coupled aerosol and tracer transport model to the brazilian developments on the regional atmospheric modeling system (CATT-BRAMS). part 1: Model description and evaluation. Atmos. Chem. Phys. Discuss., v. 9, n. 8, p. 2843-2861, 2009. 